\title{
Vacuolar Proton Pyrophosphatase Is Required for High Magnesium Tolerance in Arabidopsis
}

\author{
Yang Yang ${ }^{1}$, Ren-Jie Tang ${ }^{2}$, Baicong Mu ${ }^{1}\left(\mathbb{D}\right.$, Ali Ferjani ${ }^{3}{ }^{\circledR}$, Jisen Shi ${ }^{4}$, Hongxia Zhang ${ }^{5}$, \\ Fugeng Zhao ${ }^{1}$, Wen-Zhi Lan ${ }^{1, *(1)}$ and Sheng Luan ${ }^{2, *}$
}

1 Nanjing University-Nanjing Forestry University Joint Institute for Plant Molecular Biology, College of Life Sciences, Nanjing University, Nanjing 210093, China; yangyang_1604@163.com (Y.Y.); mubaicong@smail.nju.edu.cn (B.M.); fgzhao@nju.edu.cn (F.Z.)

2 Department of Plant and Microbial Biology, University of California, Berkeley, CA 94720, USA; rjtang@berkeley.edu

3 Department of Biology, Tokyo Gakugei University, Koganei, Tokyo 184-8501, Japan; ferjani@u-gakugei.ac.jp

4 Nanjing University-Nanjing Forestry University Joint Institute for Plant Molecular Biology, Key Laboratory of Forest Genetics and Biotechnology, Nanjing Forestry University, Nanjing 210037, China; jshi@njfu.edu.cn

5 College of Agriculture, Ludong University, Yantai 264025, China; hxzhang@sibs.ac.cn

* Correspondence: lanw@nju.edu.cn (W.-Z.L.); sluan@berkeley.edu (S.L.); Tel.: +86-025-8968-1357 (W.-Z.L.); +1-510-642-6306 (S.L.)

Received: 24 October 2018; Accepted: 11 November 2018; Published: 16 November 2018

\begin{abstract}
Magnesium $\left(\mathrm{Mg}^{2+}\right)$ is an essential nutrient in all organisms. However, high levels of $\mathrm{Mg}^{2+}$ in the environment are toxic to plants. In this study, we identified the vacuolar-type $\mathrm{H}^{+}$-pyrophosphatase, AVP1, as a critical enzyme for optimal plant growth under high-Mg conditions. The Arabidopsis avp1 mutants displayed severe growth retardation, as compared to the wild-type plants upon excessive $\mathrm{Mg}^{2+}$. Unexpectedly, the avp1 mutant plants retained similar $\mathrm{Mg}$ content to wild-type plants under either normal or high Mg conditions, suggesting that AVP1 may not directly contribute to $\mathrm{Mg}^{2+}$ homeostasis in plant cells. Further analyses confirmed that the avp 1 mutant plants contained a higher pyrophosphate (PPi) content than wild type, coupled with impaired vacuolar $\mathrm{H}^{+}$-pyrophosphatase activity. Interestingly, expression of the Saccharomyces cerevisiae cytosolic inorganic pyrophosphatase1 gene IPP1, which facilitates PPi hydrolysis but not proton translocation into vacuole, rescued the growth defects of avp 1 mutants under high-Mg conditions. These results provide evidence that high-Mg sensitivity in avp1 mutants possibly resulted from elevated level of cytosolic PPi. Moreover, genetic analysis indicated that mutation of $A V P 1$ was additive to the defects in $m g t 6$ and $c b l 2 c b l 3$ mutants that are previously known to be impaired in $\mathrm{Mg}^{2+}$ homeostasis. Taken together, our results suggest AVP1 is required for cellular PPi homeostasis that in turn contributes to high-Mg tolerance in plant cells.
\end{abstract}

Keywords: vacuolar $\mathrm{H}^{+}$-pyrophosphatase; AtAVP1; cellular PPi homeostasis; high-Mg tolerance

\section{Introduction}

Inorganic pyrophosphate (PPi) is an intermediate compound generated by a wide range of metabolic processes, including biosynthesis of various macromolecules such as proteins, DNA, RNA, and polysaccharides [1]. Being a high-energy phosphate compound, PPi can serve as a phosphate donor and energy source, but it can, at high levels, become inhibitory to cellular metabolism [2-4]. To maintain an optimal PPi level in the cytoplasm, timely degradation of excessive PPi is carried out by two major types of enzymes: soluble inorganic pyrophosphatases (sPPases) and proton-translocating membrane-bound pyrophosphatases $\left(\mathrm{H}^{+}\right.$-PPases) $[1,5,6]$. The importance of maintaining an optimal 
cellular PPi level has been demonstrated in several different organisms. Genetic mutations that lead to the absence of sPPase activity affects cell proliferation in Escherichia coli [7]. In yeast, inorganic pyrophosphatase is indispensable for cell viability because loss of its function results in cell cycle arrest and autophagic cell death associated with impaired $\mathrm{NAD}^{+}$depletion $[8,9]$.

In Arabidopsis, a tonoplast-localized proton-pumping pyrophosphatase AVP1 was shown to be the key enzyme for cytosolic PPi metabolism in different cell types of various plants [10-12]. This enzyme activity has been correlated with the important function that AVP1 plays in many physiological processes $[1,13,14]$. Arabidopsis fugu 5 mutants lacking functional AVP1 show elevated levels of cytosolic PPi and display heterotrophic growth defects resulting from the inhibition of gluconeogenesis [13,15]. This important role in controlling PPi level in plant cells is reinforced by a recent study showing that higher-order mutants defective in both tonoplast and cytosolic pyrophosphatases display much severe phenotypes including plant dwarfism, ectopic starch accumulation, decreased cellulose and callose levels, and structural cell wall defects [16]. Moreover, the tonoplast-localized $\mathrm{H}^{+}$-PPase AVP1 appears to be a predominant contributor to the regulation of cellular PPi levels because the quadruple knockout mutant lacking cytosolic PPase isoforms ppa1 ppa 2 ppa 4 ppa 5 showed no obvious phenotypes [16]. Interestingly, in companion cells of the phloem, AVP1 was also shown to be localized to the plasma membrane [17] and function as a PPi synthase that contribute to phloem loading, photosynthate partitioning, and energy metabolism [18-20]. On the other hand, AVP1 is also believed to contribute to the establishment of electrochemical potential across the vacuole membrane, which is important for subsequent vacuolar secondary transport and ion sequestration [21,22]. Constitutive overexpression of AVP1 improves the growth and yield of diverse transgenic plants under various abiotic stress conditions-including drought, salinity, as well as phosphorus $(\mathrm{P})$ and nitrogen $(\mathrm{N})$ deficiency_although the mechanism remains to be fully understood [23-27]. Taken together, AVP1 serves as a multi-functional protein involved a variety of physiological processes in plants, some of which await to be fully understood.

Magnesium $(\mathrm{Mg})$ is an essential macronutrient for plant growth and development, functioning in numerous biological processes and cellular functions, including chlorophyll biosynthesis and carbon fixation $[28,29]$. Either deficiency or excess of $\mathrm{Mg}$ in the soil could be detrimental to plant growth and therefore plants have evolved multiple adaptive mechanisms to maintain cellular $\mathrm{Mg}$ concentration within an optimal range [30]. In higher plants, the most well-documented $\mathrm{Mg}^{2+}$ transporters (MGTs) belong to homologues of bacterial CorA superfamily and are also called "MRS2" based on their similarity to yeast Mitocondrial RNA splicing 2 protein [31,32]. Several members of the MGT family mediate $\mathrm{Mg}^{2+}$ transport in bacteria or yeast as indicated by functional complementation as well as ${ }^{63} \mathrm{Ni}$ tracer assay [31-33]. In plants, they have been shown to play vital roles in $\mathrm{Mg}^{2+}$ uptake, translocation, and homeostasis associated with their different subcellular localizations and diverse tissue-specific expression patterns [30]. For instance, MGT2 and MGT3 are tonoplast localized and possibly involved in $\mathrm{Mg}^{2+}$ partitioning into mesophyll vacuoles [34]; MGT4, MGT5, and MGT9 are strongly expressed in mature anthers and play a crucial role in pollen development and male fertility [35-38]. MGT6 and MGT7 are shown to be most directly involved in Mg homeostasis because knocking-down or knocking-out either of the genes leads to hypersensitivity to low Mg conditions [33,39]. MGT6 encodes a plasma membrane-localized high-affinity $\mathrm{Mg}^{2+}$ transporter and mediates $\mathrm{Mg}^{2+}$ uptake in root hairs, particularly under Mg-limited conditions [39]. MGT7 is also preferentially expressed in roots and loss-of-function of MGT7 caused poor seed germination and severe growth retardation under low-Mg conditions [33]. Double mutant of $m g t 6$ and $m g t 7$ displayed a stronger phenotype than single mutants, suggesting that MGT6 and MGT7 may be synergistic in controlling Mg homeostasis in low-Mg environment conditions [40].

In contrast to considerable research on $\mathrm{Mg}$ transport and homeostasis under $\mathrm{Mg}$ deficient conditions, the regulatory mechanisms required for adaptation to excessive external $\mathrm{Mg}$ remain poorly understood. Recent studies suggested that MGT6 and MGT7 are essential for plants to adapt to both normal and high $\mathrm{Mg}$ conditions [40,41]. The $m g t 6$ mutant displayed dramatic growth defects with 
a decrease in cellular $\mathrm{Mg}$ content in the shoot, when grown under high $\mathrm{Mg}^{2+}$. Grafting experiments further suggested a shoot-based mechanism for $\mathrm{Mg}^{2+}$ detoxification although the exact role of MGT6 in this process is still not clear. More importantly, a core regulatory pathway consisting of two calcineurin B-like Ca sensors (CBL2 and CBL3) partnering with four CBL-interacting protein kinases (CIPK; CIPK3/9/23/26) has been established that allows plant cells to sequester $\mathrm{Mg}^{2+}$ into plant vacuoles, thereby protecting plant cells from high $\mathrm{Mg}^{2+}$ toxicity [42]. In this study, we identified the tonoplast pyrophosphatase, AVP1, as an important component in high $\mathrm{Mg}^{2+}$ tolerance in Arabidopsis. Furthermore, by analyzing the avp1-4 mgt6 double mutant and avp1-4 cbl2 cbl3 triple mutant, we showed that the role of AVP1 in high-Mg tolerance was independent of previously reported MGT6 or $\mathrm{CBL} / \mathrm{CIPK}-$ mediated pathway. Instead, our results suggested a novel link between high $\mathrm{Mg}^{2+}$ stress and PPi homeostasis in plants.

\section{Results}

\subsection{The avp1 Mutant Is Hypersensitive to High External Magnesium Conditions}

The originally reported T-DNA insertional mutant avp1-1 contains an additional T-DNA insertion causing phenotypes unrelated to AVP1 mutation [22,43]. We thus characterized another T-DNA insertion line avp1-4 (GK-596F06) for this study. The avp1-4 mutant carried a T-DNA insertion in the third exon of AVP1 as further confirmed by PCR analysis and DNA sequencing (Figure 1a). The avp1-4 homozygous mutants lacked detectable AVP1 transcripts (Figure S1c), and its tonoplast PPi hydrolysis activity was considerably diminished, to only $10 \%$ of wild type (Figure S1d). Compared with wild-type plants (Col-0), avp1-4 mutants exhibited no obvious phenotypic changes during the life cycle including vegetative and reproductive periods (Figure S1e), which is quite different from avp1-1 [43], because pleiotropic phenotypes observed in avp1-1 are caused by mutation in the GNOM (At1g13980) gene [22]. We examined the phenotype of avp1-4 plants under multiple ionic stress conditions and found that avp1-4 mutant and wild-type seedlings grew similarly on the MS medium and did not show hypersensitive response to most of the ionic stresses such as $60 \mathrm{mM} \mathrm{Na}^{+}, 60 \mathrm{mM} \mathrm{K}^{+}$, $40 \mathrm{mM} \mathrm{Ca}^{2+}, 100 \mu \mathrm{M} \mathrm{Zn}^{2+}, 40 \mu \mathrm{M} \mathrm{Cu}^{2+}$, or $100 \mu \mathrm{M} \mathrm{Fe}^{3+}$ (Figure S2). However, the growth of avp1-4 seedlings were severely impaired when $20 \mathrm{mM} \mathrm{MgCl}_{2}$ was supplemented (Figure S2). To validate the hypersensitivity of avp1-4 to $\mathrm{MgCl}_{2}$, we grew the seedlings of the mutant together with the wild-type plants on the 1/6 MS medium containing various levels of $\mathrm{Mg}^{2+}$, the avp1-4 mutant plants were clearly stunted as compared with Col-0 (Figure 1b), although the primary root length of avp1 was comparable to that of Col-0 (Figure 1d). In addition, we also studied one more mutant allele of AVP1 gene in the Wassilewskija (Ws) background, designated as avp1-3, and another three mutant alleles of AVP1, fugu5-1, fugu5-2, and fugu5-3 in the Col-0 background [13] (Figure 1a). Measurements of seedling fresh weight confirmed a severe growth inhibition by $8 \mathrm{mM} \mathrm{MgCl} 2$ in both avp1-4 and avp1-3 mutants, as compared with their respective wild-type counterparts (Figure 1e). Consistently, we also found that high-Mg sensitivity phenotypes in the three fugu 5 mutants were comparable to those in avp1-4 (Figure 1c). Together, these results suggested that AVP1 is required for $\mathrm{Mg}^{2+}$ tolerance in Arabidopsis.

\subsection{The Enzymatic Pyrophosphatase Activity Is Required for High-Mg Tolerance in Plants}

To verify that the observed phenotypes in the avp1 mutants are caused by a defect in AVP1, we conducted a complementation test in avp1-4 background. A coding sequence fragment of AVP1 was introduced into the avp1-4 mutant, and several homozygous transgenic lines were obtained (Figure S3a). Phenotypic analysis of two representative lines showed that oblong-shaped cotyledons of avp1-4 when germinated on MS media containing low sucrose or in soil were fully restored to normal shape (Figure S3b). In addition, seedling growth defects of avp1-4 under high-Mg conditions were also completely rescued (Figure 2a). Root length and shoot fresh weight of the transgenic lines under high $\mathrm{Mg}$ conditions were similar to those of the wild type (Figure 2b,c). These data further confirmed that 
loss-of-function in AVP1 was indeed the causal mutation for the high-Mg hypersensitive phenotype of avp1-4.

(a)

(a) ${ }_{\text {ATG }}$

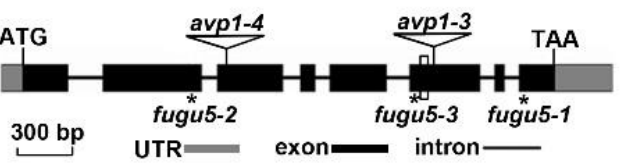

(b)

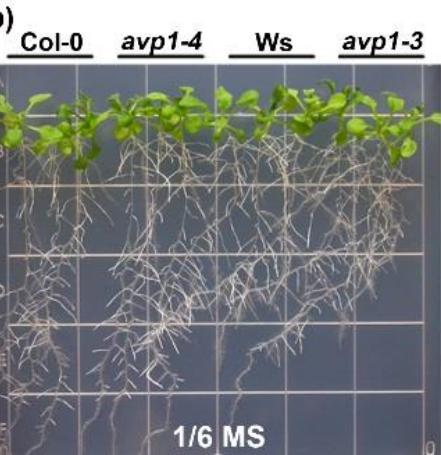

(c)

Col-0 fugu5-1 fugu5-2 fugu5-3
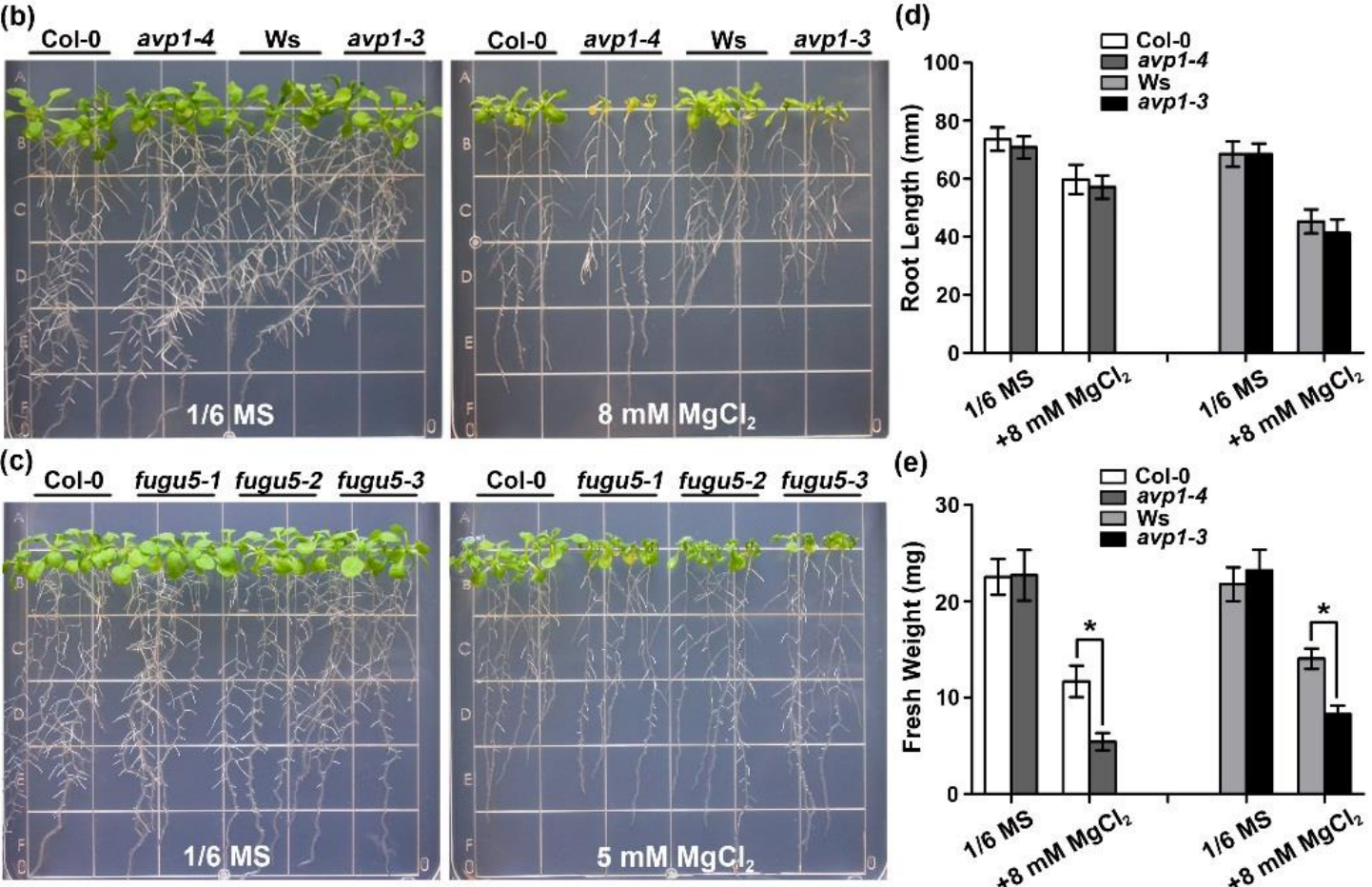

(e)

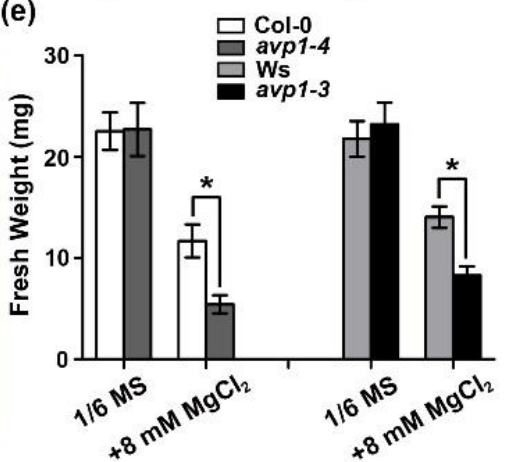

Figure 1. The avp1 mutant plants are hypersensitive to high-Mg conditions. (a) Schematic diagram of the AVP1 gene. Coding regions are depicted as black boxes, and the 5' or $3^{\prime}$ UTRs are shown as shaded boxes and lines represent introns to scale. The molecular lesion in each of the five loss-of-function avp 1 alleles is indicated by open triangles or asterisks. (b) Growth phenotype of wild types Col-0 and Ws and corresponding mutant plants avp1-4 and avp1-3 under different ionic stress conditions. Five-day-old seedlings were transferred onto 1/6 MS medium or 1/6 MS medium supplemented with 8 $\mathrm{mM} \mathrm{MgCl} 2$. Photographs were taken on the 10th day after transfer. (c) Growth phenotype of Col-0 and three fugu 5 mutant alleles on 1/6 MS medium or 1/6 MS medium supplemented with $5 \mathrm{mM} \mathrm{MgCl}_{2}$. (d) Root length and (e) fresh weight of seedlings on the 10th day after transfer. Data are presented as the mean \pm SD of four replicate experiments. Asterisks indicate statistically significant differences compared with the Col-0 or Ws (Student's $t$-test, ${ }^{*} p<0.05$ ).

Reducing the PPi concentration in the cytoplasm and increasing the acidification of vacuoles represent the two main biochemical functions of AVP1. In order to dissect if both activities are required in this specific high $\mathrm{Mg}^{2+}$-associated process, we resorted to the transgenic line expressing yeast IPP1 gene under the control of the AVP1 promoter in the fugu5-1 mutant background [13]. IPP1 is a cytosolic soluble protein which is not capable of translocating $\mathrm{H}^{+}$, thus decoupling the hydrolysis and proton pump activities. Interestingly, our results showed that the severely retarded growth of fugu5-1 mutant plants under high-Mg conditions was completely recovered by expression of the IPP1 gene (Figure 2d). The quantitative analysis of seedling fresh weight confirmed the complementation (Figure 2e,f).

To extend the phenotypic analysis of the avp1 mutants in mature plants, we examined the phenotype of avp 1 mutants using hydroponic culture system. Consistent with the patterns of plant growth on agar plates, the mutant plants exhibited a pronounced growth defect (Figure $2 \mathrm{~g}$ ) than wild-type plants in the hydroponic solutions supplemented with $15 \mathrm{mM}$ external $\mathrm{Mg}^{2+}$, as revealed by 
much lower fresh weight (Figure 2h) and lower chlorophyll content (Figure 2i). The IPP1 transgenic line also behaved like wild-type plants but not avp 1 mutant under this condition, suggesting that PPi hydrolysis is the key function that AVP1 plays in high-Mg adaptation.

(a)

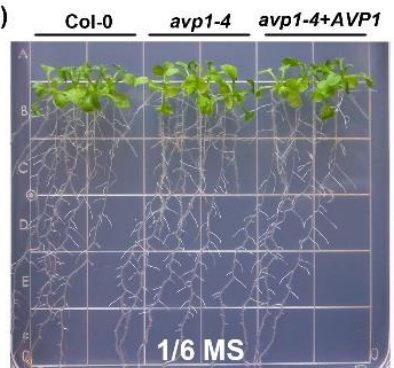

(d)

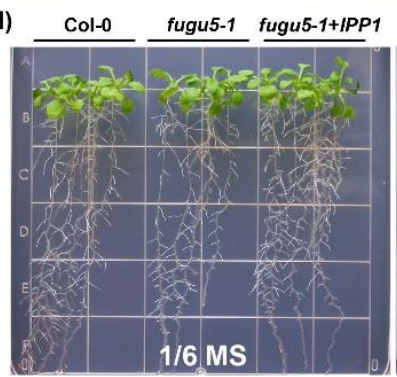

(g)

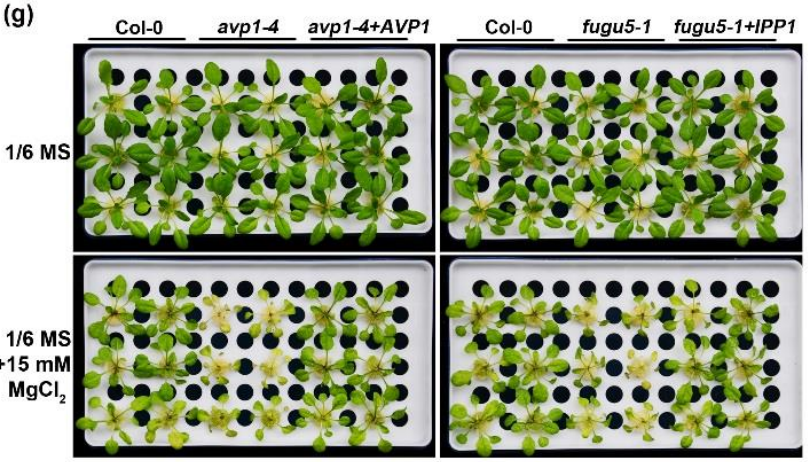

(b)

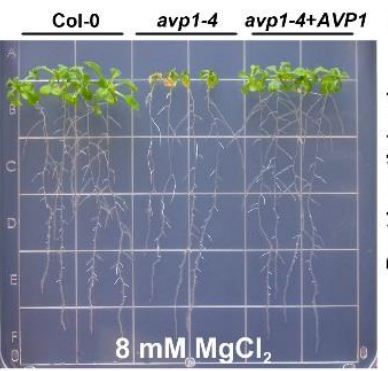

Col-0 fugu5-1 fugu5-1+IPP1

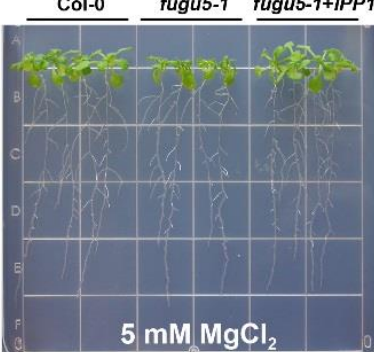

$\mathrm{mM} \mathrm{MgCl}_{2}$

fugu5-1 fugu5-1+IPP

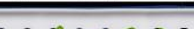

(h)

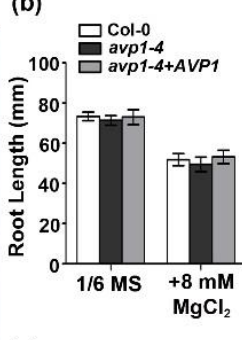

(e) (f)

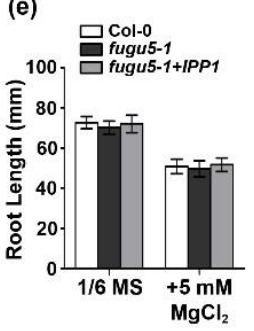

(c)

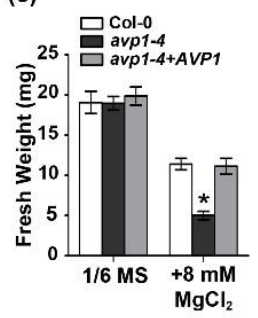

(f)
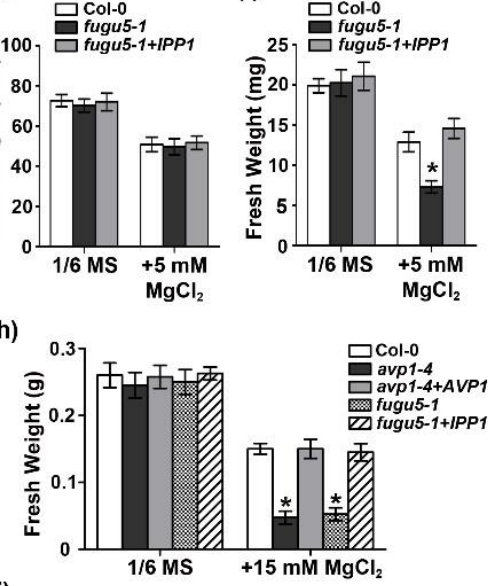

(i)

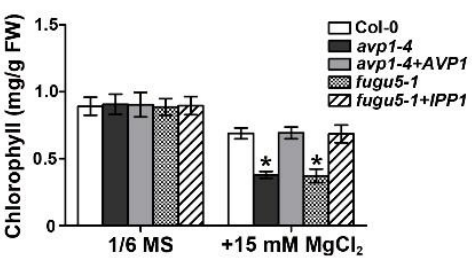

Figure 2. Functional complementation of avp1-4 and fugu5-1 under high-Mg stress grown on agar plates or in hydroponic culture. (a) Growth phenotype of wild type Col-0, avp1-4 and corresponding complementary line avp1-4+AVP1 on 1/6 MS medium or 1/6 MS medium supplemented with $8 \mathrm{mM}$ $\mathrm{MgCl}_{2}$. Photographs were taken on the 10th day after transfer. (b) Root length and (c) fresh weight of seedlings described in (a) on the 10th day after transfer. (d) Growth phenotype of wild type (Col-0), fugu5-1 and corresponding complementary line fugu5-1+IPP1 on 1/6 MS medium or 1/6 MS medium supplemented with $5 \mathrm{mM} \mathrm{MgCl}_{2}$. Photographs were taken on the 10th day after transfer. (e) Root length and (f) fresh weight of seedlings described in (d) on the 10th day after transfer. (g) Effect of $\mathrm{Mg}^{2+}$ concentration on growth of Col-0, avp1-4, fugu5-1, and corresponding complemented lines. Two-week-old plants grown in 1/6 MS hydroponic culture were transferred onto 1/6 MS or 1/6 MS hydroponic culture supplemented with $15 \mathrm{mM} \mathrm{MgCl}_{2}$. Photographs were taken on the 5 th day after transfer. (h) Fresh weight and (i) chlorophyll content of the plants of various genotypes described in (g). Data are presented as the mean \pm SD of four replicate experiments. Asterisks indicate statistically significant differences compared with the Col-0 (Student's $t$-test, * $p<0.05$ ).

To address the contribution of PPi hydrolysis activity to high-Mg tolerance, we directly measured V-PPase activity and PPi content under normal and high-Mg conditions. Under normal conditions, PPi hydrolysis activity of two avp 1 mutant alleles was reduced by $\sim 85 \%$, whereas activity from two complementary lines was comparable to the wild-type control (Figure 3a). Consistently, the amount of PPi from both mutants was increased by $~ 50 \%$ (Figure 3b). After grown for three days on $15 \mathrm{mM}$ $\mathrm{Mg}^{2+}$, all the plants displayed reduced PPi hydrolysis activity and higher PPi content. However, the 
PPi elevation of mutant plants during high $\mathrm{Mg}^{2+}$ stress was significantly higher than that of wild type (Figure 3). Altogether, these results strongly indicate that the dampened hydrolysis of cytosolic PPi is the major reason for the increased $\mathrm{Mg}$ sensitivity in the avp1 mutants.
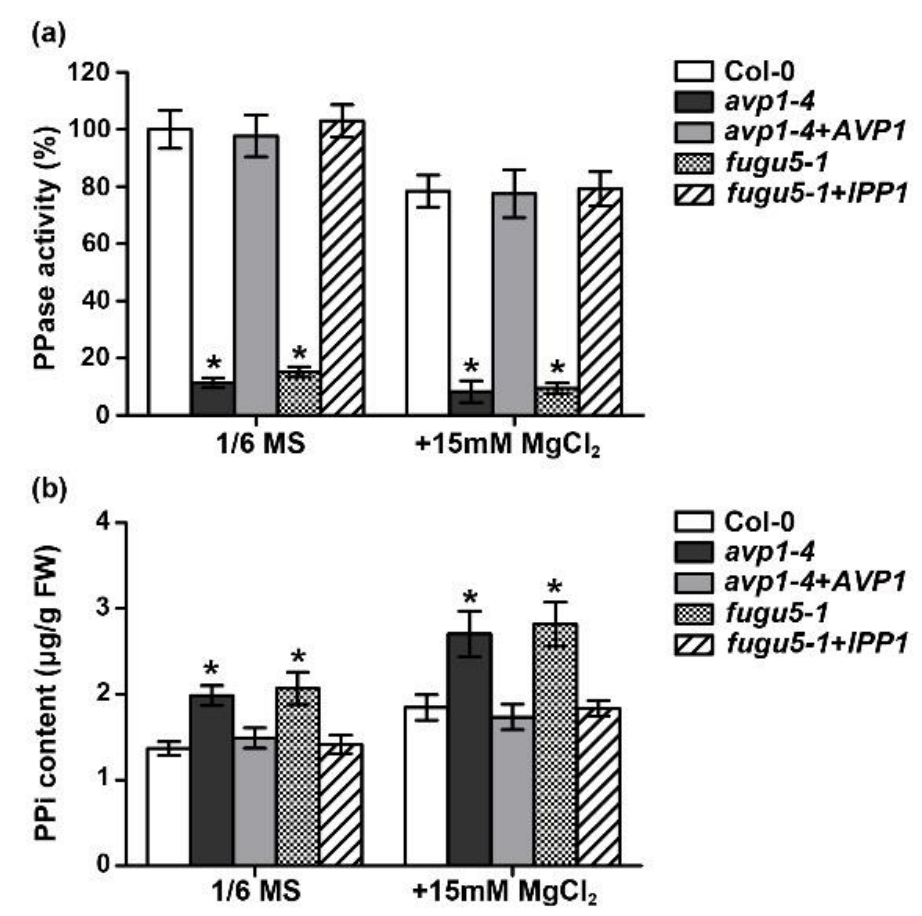

Figure 3. V-PPase activities and the contents of PPi under different $\mathrm{Mg}^{2+}$ conditions. (a) $\mathrm{H}^{+}$-PPase hydrolysis activity was determined from microsomal membranes of two-week old plants of wild type (Col-0), mutants (avp1-4 and fugu5-1) and complementary lines (avp1-4+AVP1 and fugu5-1+IPP1) grown in hydroponic culture. Results are shown as percentage of the Col-0 control activity. Values are mean \pm SD of three replicate experiments. (b) PPi content of seedlings under different $\mathrm{Mg}^{2+}$ conditions. Seedlings grown under the same conditions and collected at the same stage as described in (a) were used for the quantification of PPi. Values are mean \pm SD from triplicate experiments. Asterisk indicates significant difference compared with the wild type (Student's $t$-test, ${ }^{*} p<0.05$ ).

\subsection{The avp1 Mutant Is Not Compromised in $\mathrm{Mg}^{2+}$ Homeostasis}

To assess whether increased $\mathrm{Mg}^{2+}$ sensitivity in the avp1 mutant is associated with $\mathrm{Mg}^{2+}$ homeostasis, we measured the $\mathrm{Mg}$ content in wild-type (Col-0 and Ws) and mutant plants (avp1-4 and avp1-3) using ICP-MS. When $8 \mathrm{mM} \mathrm{Mg}^{2+}$ was added to the growth medium, $\mathrm{Mg}$ content in either shoot or root in all the plants was strikingly elevated, but no significant difference between wild-type and mutant plants in Mg content was observed. (Figure 4a,b). Considering Ca and Mg often affect each other in their uptake and transport [30], we also measured the Ca content in the same plants. Consistent with $\mathrm{Mg}$-Ca antagonism, the Ca content in both wild-type and avp1 mutant plants was evidently lower when plants were grown under high external $\mathrm{Mg}^{2+}$ conditions, but Ca content in the shoots and roots in avp1 mutants was similar to that in wild-type plants (Figure 4c,d). These data suggest that both $\mathrm{Mg}$ and Ca homeostasis are not altered in the avp1 mutants, which are consistent with the earlier conclusion that PPi hydrolysis rather than vacuolar acidification is responsible for AVP1 function under high-Mg stress.

\subsection{AVP1 and MGT6 Function Independently in High-Mg Tolerance in Arabidopsis}

In Arabidopsis, the magnesium transporter MGT6 is important for controlling plant $\mathrm{Mg}^{2+}$ homeostasis and adaptation to both low- and high-Mg conditions [39-41]. To investigate the functional interaction between AVP1 and MGT6, we created a double mutant that lacks both AVP1 and MGT6 
transcripts (Figure 5a). We next tested the sensitivity of avp1-4 mgt6 double mutant to high external $\mathrm{Mg}$ conditions. When grown on the $1 / 6 \mathrm{MS}$ medium containing $0.25 \mathrm{mM} \mathrm{Mg}^{2+}$, the $m g t 6$ and avp 1-4 mgt6 plants showed obvious growth retardation compared with Col- 0 and avp $1-4$ seedlings, resulting from $m g t 6$ mutation that renders plants hypersensitive to low $\mathrm{Mg}^{2+}$ (Figure $5 \mathrm{~b}, \mathrm{f}$ ). When the medium $\mathrm{Mg}^{2+}$ levels reached $1 \mathrm{mM}$, the growth of $m g t 6$ and avp1-4 mgt6 mutants appeared comparable to that of wild-type (Figure $5 c, f)$. Notably, in the presence of high $\mathrm{Mg}$ levels such as $4 \mathrm{mM}$ and $6 \mathrm{mM} \mathrm{Mg} \mathrm{Mg}^{2+}$, avp1-4 mgt6 double mutant exhibited more severe inhibition of shoot growth with significantly lower fresh weight (Figure 5d-f) and more reduced chlorophyll content (Figure 5g) as compared to either $m g t 6$ or avp 1 single mutant. The enhanced sensitivity of the avp1-4 mgt6 double mutant suggest that AVP1 and MGT6 may represent two independent functions that are required for plant tolerance to high $\mathrm{Mg}^{2+}$ stresses.

(a)

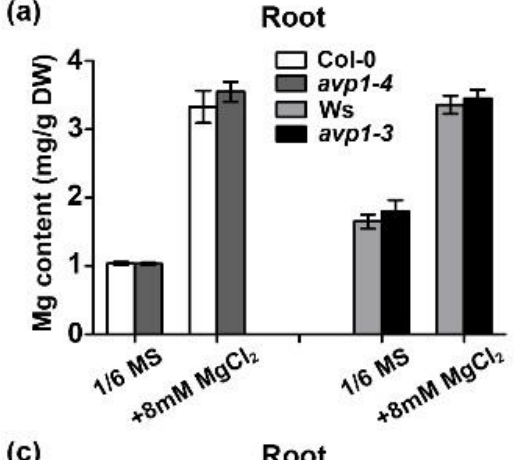

(c)

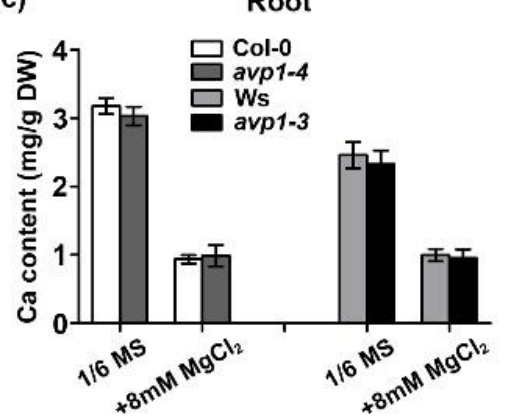

(b)

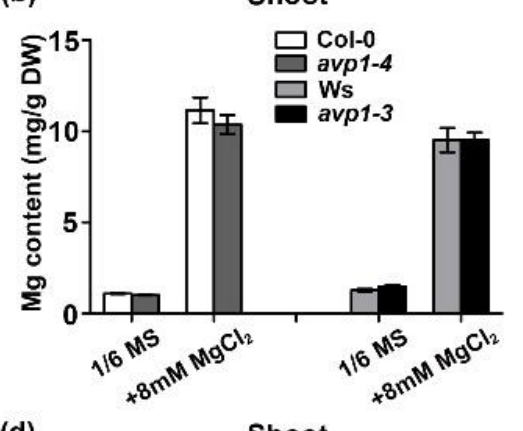

(d)

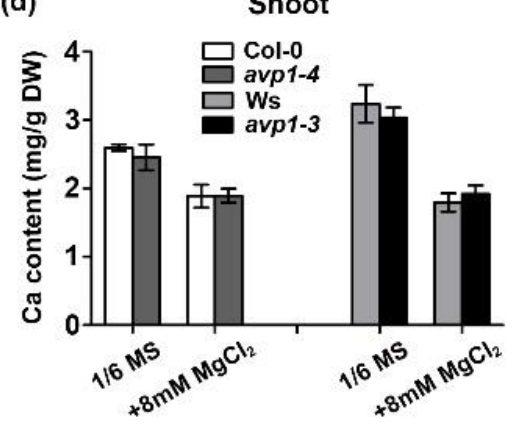

Figure 4. $\mathrm{Mg}$ and Ca content in the avp1 mutant under different $\mathrm{Mg}^{2+}$ conditions. (a,b) $\mathrm{Mg}$ content in the root (a) and shoot (b) under different $\mathrm{Mg}^{2+}$ regimes. (c,d) Ca content in the root (c) and shoot (d) under different $\mathrm{Mg}^{2+}$ regimes. Data are presented as the mean $\pm \mathrm{SD}$ of triplicate experiments.

\subsection{Hypersensitivity of avp1-4 cbl2 cbl3 Triple Mutant to High External $\mathrm{Mg}^{2+}$ Concentrations}

The vacuolar $\mathrm{Mg}^{2+}$ sequestration regulated by tonoplast-localized CBL-CIPK modules is established as a key mechanism in detoxifying excessive $\mathrm{Mg}^{2+}$ in plant cells [42]. Since AVP1 also resides in the tonoplast [44], it is relevant to examine whether the hypersensitivity of avp 1 mutants would be somehow associated with the vacuolar $\mathrm{Mg}^{2+}$ sequestration controlled by CBL2 and CBL3. To this end, we constructed an avp1-4 cbl2 cbl3 triple mutant (Figure 6a) and subsequently characterized its phenotype in the presence of various $\mathrm{Mg}^{2+}$ concentrations (Figure $6 \mathrm{~b}-\mathrm{e}$ ). The wild type and the three mutants, avp1-4, cbl2 cbl3, and avp1-4 cbl2 cbl3, grow normally on 1/6 MS containing $0.25 \mathrm{mM}$ or $1 \mathrm{mM} \mathrm{Mg}^{2+}$. Under high $\mathrm{Mg}^{2+}$ conditions $(4 \mathrm{mM}, 6 \mathrm{mM})$, both avp1-4 and cbl2 cbl3 mutants displayed severe growth retardation, whereas avp $1-4$ cbl2 cbl3 triple mutant hardly survived, displaying an even more sensitive phenotype to high $\mathrm{Mg}^{2+}$ than either of the single mutants (Figure 6d,e). Measurements of seedling fresh weight and leaf chlorophyll content confirmed much more severe growth inhibition by $4 \mathrm{mM}$ and $6 \mathrm{mM} \mathrm{MgCl}_{2}$ in the avp1-4 cbl2 cbl3 triple mutant (Figure $6 \mathrm{f}, \mathrm{g}$ ). We concluded that the $\mathrm{Mg}$ hypersensitivity of avp1 mutants results from altered processes independent of vacuolar $\mathrm{Mg}^{2+}$ partitioning pathway regulated by CBL2 and CBL3. 

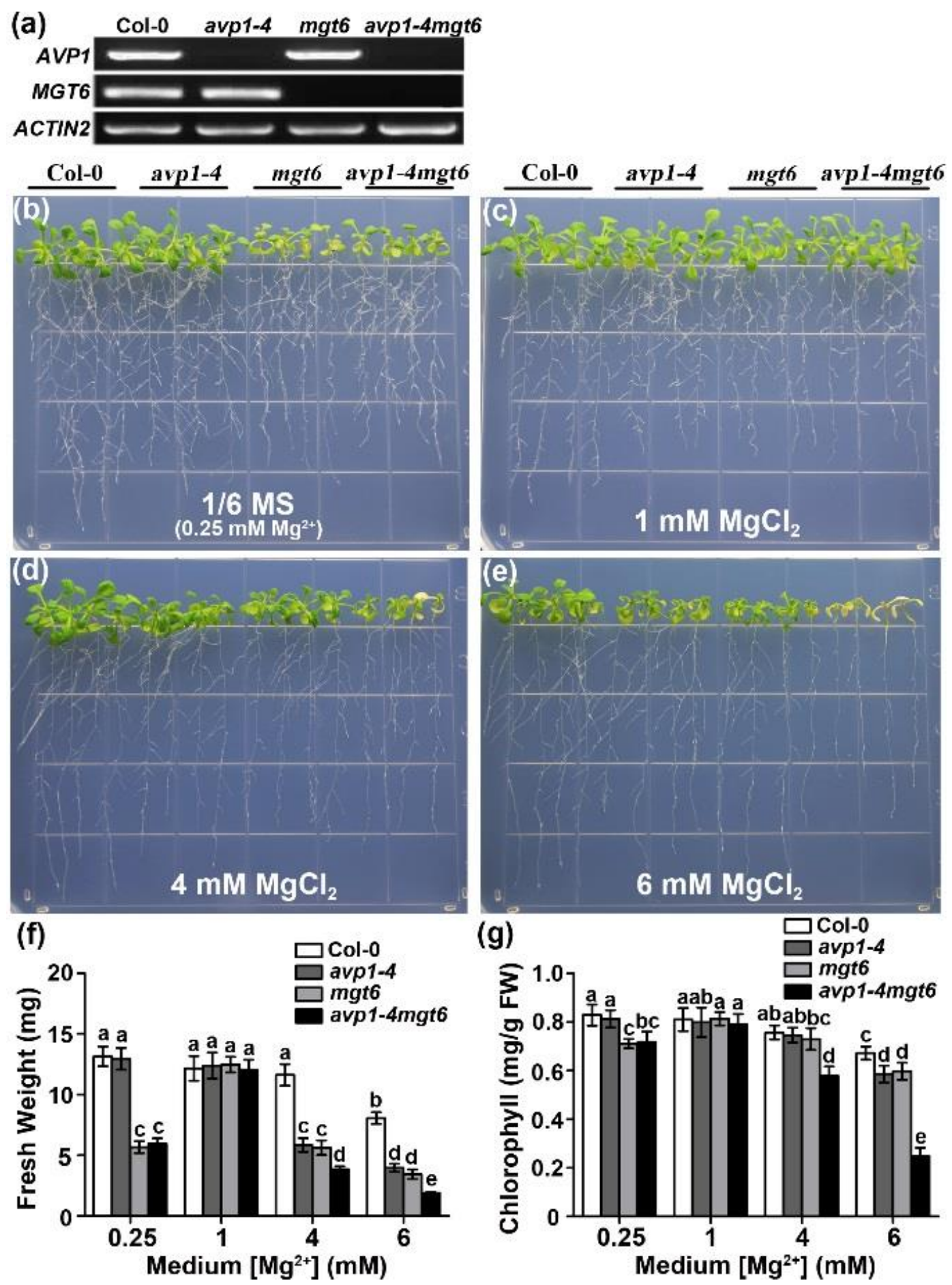

Figure 5. Phenotypic analysis of $\mathrm{Mg}^{2+}$ sensitivity in the avp1-4 mgt6 double mutant. (a) RT-PCR analysis of AVP1 and MGT6 gene expression in wild-type Col-0, homozygous avp1-4 or mgt6 single mutant and the avp1-4 mgt6 double mutant. (b-e) Phenotypic analysis of $\mathrm{Mg}^{2+}$ sensitivity in avp1-4, mgt6, and avp1-4 mgt6 mutants. (f) Fresh weight of seedlings on the 10th day after transfer. (g) Chlorophyll content of seedlings on the 10th day after transfer. Data are mean \pm SD from triplicate experiments. Any pair of genotypes/treatments that do not share the same letter are significantly different $(p<0.05)$ based on a Duncan's multiple range test. 

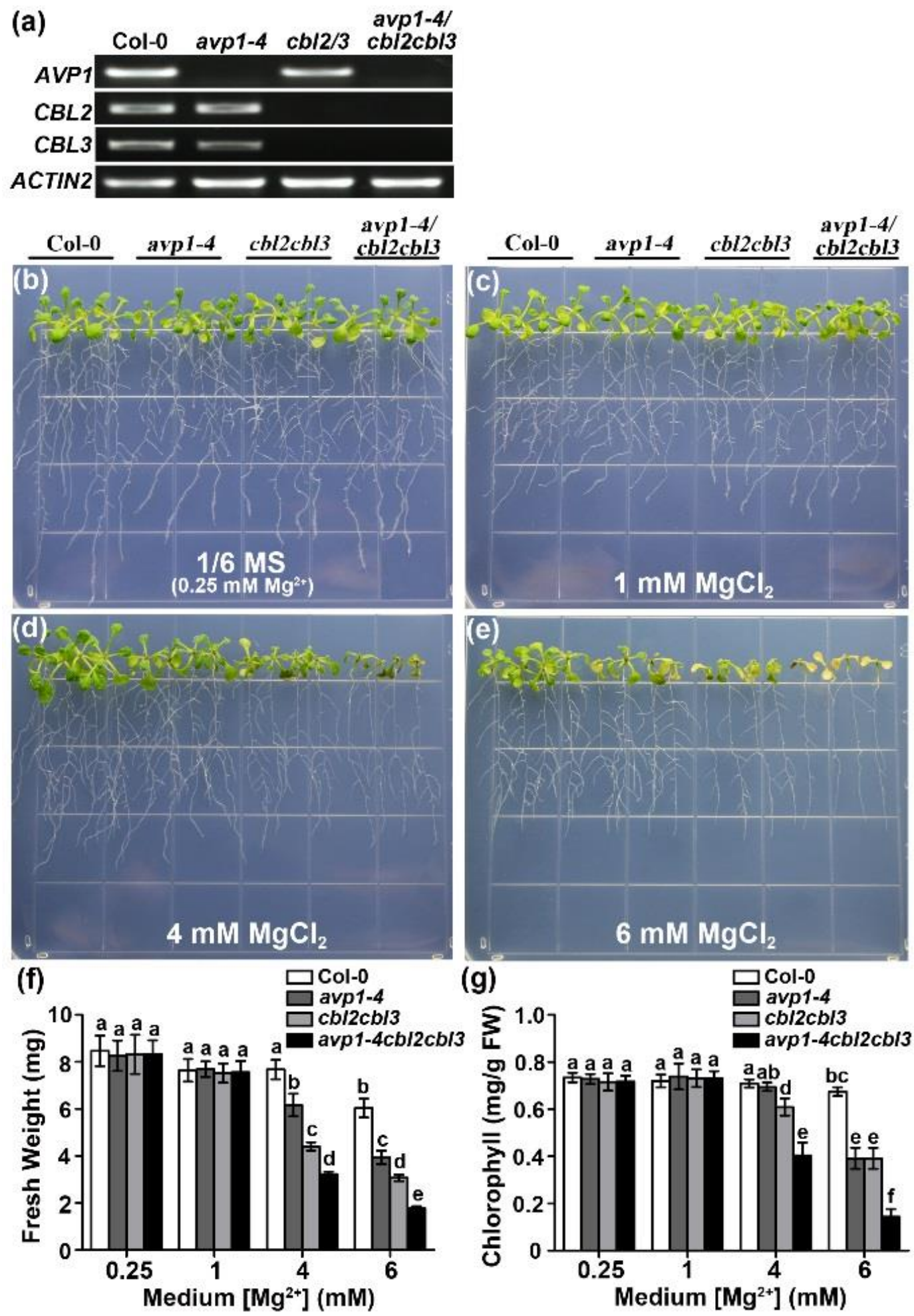

Figure 6. Phenotypic analysis of $\mathrm{Mg}^{2+}$ sensitivity in the avp1-4 cbl2 cbl3 triple mutant. (a) RT-PCR analysis of $A V P 1, C B L 2$, and CBL3 gene expression in wild type Col-0, avp1-4 single mutant, cbl2 cbl3 double mutant and avp1-4 cbl2 cbl3 triple mutant. (b-e) Phenotypic analysis of $\mathrm{Mg}^{2+}$ sensitivity in avp1-4, cbl2 cbl3, and avp1-4 cbl2 cbl3 mutants. (f) Fresh weight of seedlings on the 10th day after transfer. (g) Chlorophyll content of seedlings on the 10th day after transfer. Data are mean \pm SD from triplicate experiments. Any pair of genotypes/treatments that do not share the same letter are significantly different $(p<0.05)$ based on a Duncan's multiple range test. 


\section{Discussion}

Although $\mathrm{Mg}$ is an essential macronutrient required for plant growth, high concentrations of environmental $\mathrm{Mg}^{2+}$ could be detrimental, and the targets underlying toxic effect of high-Mg are not well understood. In the present study, we characterized multiple avp 1 mutant alleles and found they were hypersensitive to high external $\mathrm{Mg}^{2+}$. This finding has not only improved our understanding of the mechanism underlying $\mathrm{Mg}^{2+}$ tolerance but also uncovered a novel physiological function of AVP1 in plants. When the plants were confronted with high Mg stress, sequestration of excessive $\mathrm{Mg}^{2+}$ into the vacuole plays a vital role in detoxification of $\mathrm{Mg}$ excess from the cytoplasm [30,45]. The AVP1 protein predominantly localized in the vacuolar membrane [44] and was a highly abundant component of the tonoplast proteome [21]. Encoded by AVP1, vacuolar $\mathrm{H}^{+}$-PPase, together with vacuolar $\mathrm{H}^{+}$-ATPase, plays a critical part in establishing the electrochemical potential by pumping $\mathrm{H}^{+}$ across the vacuolar membrane. This proton gradient, in turn, facilitates secondary fluxes of ions and molecules across the tonoplast $[21,22,27]$. Based on this well-established idea, we hypothesized that avp1 mutants may be impaired in cellular ionic homeostasis and should thus exhibit hypersensitivity to a broad range of ions. However, unexpectedly, we found that avp1 was hypersensitive only to high external $\mathrm{Mg}^{2+}$ but not to other cations (Figure S2). It was shown that overexpression of AVP1 improved plant salt tolerance in quite a few species, which was interpreted as the result of increased sequestration of $\mathrm{Na}^{+}$into the vacuole $[23,46,47]$. It is thus reasonable to speculate that the tonoplast electrochemical potential generated by AVP1 would likewise favor $\mathrm{Mg}^{2+}$ transport into vacuoles via secondary $\mathrm{Mg}^{2+} / \mathrm{H}^{+}$antiporter. Surprisingly, our subsequent experiments did not support this hypothesis and several lines of evidence suggested that the hypersensitivity of avp 1 to high $\mathrm{Mg}^{2+}$ was not due to the compromised $\mathrm{Mg}^{2+}$ homeostasis in the mutant. First, unlike other high $\mathrm{Mg}^{2+}$-sensitive mutants such as $m g t 6$ and the vacuolar $c b l / c i p k$ mutants, the $\mathrm{Mg}$ and $\mathrm{Ca}$ content in the avp 1 mutant was not altered as compared with wild type, suggesting that AVP1 may not be directly involved in $\mathrm{Mg}^{2+}$ transport in plant cells. Second, higher order mutants of the avp1-4 mgt6 double mutant and avp1-4 cbl2 cbl3 triple mutant displayed a dramatic enhancement in $\mathrm{Mg}^{2+}$ sensitivity as compared to single mutants. These genetic data strongly suggest that AVP1 does not function in the same pathway mediated by MGT6 and does not serve as a target for vacuolar CBL-CIPK. Moreover, it was previously shown that either vacuolar $\mathrm{H}^{+}$-ATPase double mutant vha-a2 vha-a3 or the $m h x 1$ mutant defective in the proposed $\mathrm{Mg}^{2+} / \mathrm{H}^{+}$antiporter was not hypersensitive to high $\mathrm{Mg}^{2+}$ [42]. These results implicate the vacuolar $\mathrm{Mg}^{2+}$ compartmentalization should be fulfilled by an unknown $\mathrm{Mg}^{2+}$ transporter/channel, whose activity is largely not dependent on the tonoplast $\Delta \mathrm{pH}$. Identification of this novel $\mathrm{Mg}^{2+}$ transport system across the tonoplast, which is probably targeted by vacuolar CBL-CIPK complexes, would be the key to understand the mechanism. Third, expression of the cytosolic soluble pyrophosphatase isoform IPP1 could fully rescue the Mg-hypersensitivity caused by AVP1 mutation. These lines of evidence pinpoint PPi hydrolysis, rather than $\triangle \mathrm{pH}$-assisted secondary ion transport and sequestration, as the major function of AVP1 in high $\mathrm{Mg}^{2+}$ adaptation.

Under high $\mathrm{Mg}$ stress conditions, a number of adaptive responses are supposed to take place in plants, including the remodeling of plant morphogenesis as well as reprogramming of the gene expression and metabolite profile. However, very little is known so far and therefore, the molecular components targeted by excessive $\mathrm{Mg}^{2+}$ in plant cells remain obscure. Here, we suggest that the concentration of cellular PPi could be responsive to external Mg supply. Our results showed that extremely high levels of $\mathrm{Mg}^{2+}$ led to inhibition of the PPase activity in Arabidopsis, which in turn, resulted in the elevation of PPi content in the cytosol. Because high level of PPi is very toxic, the efficient removal of PPi by AVP1 under high $\mathrm{Mg}^{2+}$ conditions might become one of the limiting factors for optimal plant growth. This idea is supported by the observation that avp1 mutants accumulated significantly higher PPi content under high $\mathrm{Mg}^{2+}$ conditions compared with normal conditions (Figure 3). Most importantly, heterologous expression of the soluble PPase IPP1 gene rescued high Mg-sensitive phenotype of fugu5-1 (Figure 2), which strongly suggested that high $\mathrm{Mg}^{2+}$ hypersensitivity phenotype in avp 1 mutants could primarily be attributed to impaired PPi homeostasis. 
It would be interesting to investigate how PPi concentrations vary in different $\mathrm{Mg}^{2+}$ conditions and during different plant growth stages. Recently, cytosolic soluble pyrophosphatases (AtPPa1 to AtPPa5) were identified in Arabidopsis, and were shown to physiologically cooperate with the vacuolar $\mathrm{H}^{+}$-PPase in regulating cytosolic PPi levels [16]. Future studies should clarify if this type of soluble isoenzymes is also involved in the same high-Mg adaptation process. Collectively, our findings provide genetic and physiological evidence that $A V P 1$ is a new component required for plant growth under high external $\mathrm{Mg}^{2+}$ concentrations and functions in regulating $\mathrm{Mg}^{2+}$ tolerance via PPi hydrolysis.

\section{Materials and Methods}

\subsection{Plant Materials and Growth Conditions}

Arabidopsis thaliana ecotype Columbia (Col-0) and Wassilewskija (Ws) were used as wild type in this study. The mutants fugu5-1, fugu5-2, fugu5-3, and transgenic plants fugu5-1+IPP1 were offered and characterize by Ferjani (2011) [13]. The cbl2 cbl3 double mutant was described in previous studies [48]. The T-DNA insertion mutants avp1-4 (GK-596F06) and mgt6 (SALK_205483) were obtained from the European Arabidopsis Stock Centre and the Arabidopsis Biological Resource Center. The mutant avp1-3 (FLAG_291B12) was a T-DNA insertion mutant in the Wassilewskija (Ws) background and obtained from INRA Arabidopsis T-DNA mutant library. Mutants with multiple gene-knockout events were generated by genetic crosses, and homozygous mutant plants were screened from F2 generation and identified by genomic PCR using primers listed in Supplementary Table S1.

\subsection{Phenotypic Analysis}

For on-plate growth assays, seeds of different genotypes were sterilized with $75 \%$ ethanol for $10 \mathrm{~min}$, washed in sterilized water for three times, and sown on Murashige and Skoog (MS) medium containing $2 \%$ sucrose (Sigma) and solidified with $0.8 \%$ phytoblend (Caisson Labs). The plates were incubated at $4{ }^{\circ} \mathrm{C}$ in darkness for two days and then were positioned vertically at $22{ }^{\circ} \mathrm{C}$ in growth chamber with a $14 \mathrm{~h}$ light/10 h dark photoperiod. After germination, five-day-old seedlings were transferred onto agarose-solidified media containing various ions as indicated in the figure legends and were grown under $14 \mathrm{~h}$ light $/ 10 \mathrm{~h}$ dark photoperiod.

For phenotypic assay in the hydroponics, 10-day-old seedlings geminated on MS plate were transferred to $1 / 6$ strength MS solution and were grown under the $14 \mathrm{~h}$ light $/ 10 \mathrm{~h}$ dark condition in the plant growth chamber. Fresh liquid solutions were replaced once a week. After two-week culture, the plants were treated with $1 / 6 \mathrm{MS}$ solutions supplemented with $15 \mathrm{mM} \mathrm{MgCl}_{2}$.

\subsection{Crude Membrane Preparation and Enzymatic Activity Assays}

Two-week-old hydroponically grown plants were treated with 1/6 MS solutions containing 0 or $15 \mathrm{mM} \mathrm{MgCl}_{2}$. After two-day treatment, leaves of all the plants were collected to prepare crude membrane as described previously [48]. Plant materials were ground at $4{ }^{\circ} \mathrm{C}$ with cold homogenization buffer containing $350 \mathrm{mM}$ sucrose, $70 \mathrm{mM}$ Tris- $\mathrm{HCl}$ (pH 8.0), $3 \mathrm{mM} \mathrm{Na} 2$ EDTA, $0.2 \%(w / v)$ BSA, $1.5 \%$ $(w / v)$ PVP-40, $5 \mathrm{mM}$ DTT, 10\% (v/v) glycerol, $1 \mathrm{mM}$ PMSF and $1 \times$ protease inhibitor mixture (Roche). The homogenate was filtered through four layers of cheesecloth and centrifuged at $4000 \times g$ for $20 \mathrm{~min}$ at $4{ }^{\circ} \mathrm{C}$. The supernatant was then centrifuged at $100,000 \times g$ for $1 \mathrm{~h}$. The obtained pellet was suspended in $350 \mathrm{mM}$ sucrose, $10 \mathrm{mM}$ Tris-Mes (pH 7.0), $2 \mathrm{mM}$ DTT and $1 \times$ protease inhibitor mixture.

Pyrophosphate hydrolysis was measured as described in previous studies [48]. The assay solution for PPi hydrolysis activity contained $25 \mathrm{mM}$ Tris-Mes (pH 7.5), $2 \mathrm{mM} \mathrm{MgSO}_{4}, 100 \mu \mathrm{M} \mathrm{Na}_{2} \mathrm{MoO}_{4}, 0.1 \%$ Brij 58, and $200 \mu \mathrm{M} \mathrm{Na}{ }_{4} \mathrm{P}_{2} \mathrm{O}_{7}$. PPase activity was expressed as the difference of phosphate (Pi) release measured in the absence and the presence of $50 \mathrm{mM} \mathrm{KCl}$. After incubation at $28^{\circ} \mathrm{C}$ for $40 \mathrm{~min}, 40 \mathrm{mM}$ citric acid was added to terminate reactions. For the measurement of inorganic $\mathrm{Pi}$ amount, freshly prepared AAM solution $\left(50 \%(v / v)\right.$ acetone, $2.5 \mathrm{mM}$ ammoniummolybdate, $\left.1.25 \mathrm{M} \mathrm{H}_{2} \mathrm{SO}_{4}\right)$ was added to the reaction solution, vortexed and colorimetrically examined at $355 \mathrm{~nm}$. 


\subsection{Quantification of Pyrophosphate in Plants}

Two-week-old hydroponically grown plants were transferred to 1/6 MS solutions containing 0 or $15 \mathrm{mM} \mathrm{MgCl}_{2}$. After two-day treatment, leaves of all the plants were collected and PPi was extracted from leaf tissue as described previously [49]. Leaf samples were ground to powder in liquid nitrogen, suspended with three volumes of pure water, heated at $85^{\circ} \mathrm{C}$ for $15 \mathrm{~min}$, and then centrifuged at 15,000 rpm for $10 \mathrm{~min}$. The supernatants were collected and then centrifuged at 40,000 rpm for $10 \mathrm{~min}$. The obtained supernatants were diluted with pure water and subjected to PPi assay using a PPi Assay Kit (Sigma, St. Louis, MO, USA) according to the manufacturer's instructions. Fluorescence was monitored with a Safire 2 plate reader set at $316 \mathrm{~nm}$ for excitation and $456 \mathrm{~nm}$ for emission (Tecan, Männedorf, Switzerland).

\subsection{Measurements of $\mathrm{Mg}$ and $\mathrm{Ca}$ Content}

One-week-old Arabidopsis seedlings were transferred onto 1/6-strength MS medium supplemented with 0 or $8 \mathrm{mM} \mathrm{MgCl}$. After a seven-day treatment, seedlings of wild-type and mutant plants were collected and pooled into roots and shoots. The samples were washed with $18 \mathrm{M} \Omega$ water for three to five times, dried for $48 \mathrm{~h}$ at $80^{\circ} \mathrm{C}$, milled to fine powder, weighed, and digested with concentrated $\mathrm{HNO}_{3}$ (Sigma-Aldrich, Milwaukee, WI, USA) in $100^{\circ} \mathrm{C}$ water bath for $1 \mathrm{~h} . \mathrm{Mg}^{2+}$ and $\mathrm{Ca}^{2+}$ concentrations were determined using an ICP mass spectrometer (PerkinElmer NexION 300). Each sample was tested three times.

\subsection{Statistical Analysis of the Data}

All data in this work were obtained from at least three independent experiments. Data were subjected to statistical analyses using Student's $t$-test $(p<0.05)$ or one-way analysis of variance (ANOVA) followed by Duncan's multiple range test $(p<0.05)$.

Supplementary Materials: Supplementary materials can be found at http://www.mdpi.com/1422-0067/19/ $11 / 3617 / \mathrm{s} 1$. Figure S1. Molecular identification of avp1-4 mutant. Figure S2. The avp1-4 mutant is specifically sensitive to $\mathrm{Mg}^{2+}$. Figure S3. Functional complementation of avp1-4. Table S1. Primers Used in This Study.

Author Contributions: Conceptualization, Y.Y., R.-J.T., and S.L.; Data curation, Y.Y. and R.-J.T.; Formal analysis, Y.Y. and R.-J.T.; Funding acquisition, W.-Z.L. and S.L.; Investigation, Y.Y., R.-J.T., and B.M.; Resources, A.F. and H.Z.; Supervision, J.S., F.Z., W.-Z.L., and S.L.; Writing-original draft, Y.Y. and R.-J.T.; Writing—review \& editing, A.F. and S.L.

Funding: This work was funded by National Natural Science Foundation of China 31770267 (to W.-Z.L.) and a grant from the National Science Foundation MCB-1715764 (to S.L.).

Acknowledgments: We thank the Arabidopsis Biological Resource Center, the European Arabidopsis Stock Centre and INRA Arabidopsis T-DNA mutant library for providing Arabidopsis thaliana seed stocks.

Conflicts of Interest: The authors declare no conflict of interest.

\section{References}

1. Maeshima, M. Vacuolar $\mathrm{H}^{+}$-pyrophosphatase. Biochim. Biophys. Acta 2000, 1465, 37-51. [CrossRef]

2. George, G.M.; van der Merwe, M.J.; Nunes-Nesi, A.; Bauer, R.; Fernie, A.R.; Kossmann, J.; Lloyd, J.R. Virus-induced gene silencing of plastidial soluble inorganic pyrophosphatase impairs essential leaf anabolic pathways and reduced drought stress tolerance in Nicotiana benthamiana. Plant Physiol. 2010, 154, 55-66. [CrossRef] [PubMed]

3. López-Marqués, R.L.; Pérez-Castiñeira, J.R.; Losada, M.; Serrano, A. Differential regulation of soluble and membrane-bound inorganic pyrophosphatases in the photosynthetic bacterium Rhodospirillum rubrum provides insights into pyrophosphate-based stress bioenergetics. J. Bacteriol. 2004, 186, 5418-5426. [CrossRef] [PubMed]

4. Ferjani, A.; Kawade, K.; Asaoka, M.; Oikawa, A.; Okada, T.; Mochizuki, A.; Maeshima, M.; Hirai, M.Y.; Saito, K.; Tsukaya, H. Pyrophosphate inhibits gluconeogenesis by restricting UDP-glucose formation in vivo. Sci. Rep. 2018, 8, 14696-14705. [CrossRef] [PubMed] 
5. Schulze, S.; Mant, A.; Kossmann, J.; Lloyd, J.R. Identification of an Arabidopsis inorganic pyrophosphatase capable of being imported into chloroplasts. FEBS Lett. 2004, 565, 101-105. [CrossRef] [PubMed]

6. Navarro-De la Sancha, E.; Coello-Coutiño, M.P.; Valencia-Turcotte, L.G.; Hernández-Domínguez, E.E.; Trejo-Yepes, G.; Rodríguez-Sotres, R. Characterization of two soluble inorganic pyrophosphatases from Arabidopsis thaliana. Plant Sci. 2007, 172, 796-807. [CrossRef]

7. Chen, J.; Brevet, A.; Fromant, M.; Lévêque, F.; Schmitter, J.M.; Blanquet, S.; Plateau, P. Pyrophosphatase is essential for growth of Escherichia coli. J. Bacteriol. 1990, 172, 5686-5689. [CrossRef] [PubMed]

8. Pérez-Castiñeira, J.R.; López-Marqués, R.L.; Villalba, J.M.; Losada, M.; Serrano, A. Functional complementation of yeast cytosolic pyrophosphatase by bacterial and plant $\mathrm{H}^{+}$-translocating pyrophosphatases. Proc. Natl. Acad. Sci. USA 2002, 99, 15914-15919. [CrossRef] [PubMed]

9. Serrano-Bueno, G.; Hernández, A.; López-Lluch, G.; Pérez-Castiñeira, J.R.; Navas, P.; Serrano, A. Inorganic pyrophosphatase defects lead to cell cycle arrest and autophagic cell death through $\mathrm{NAD}^{+}$depletion in fermenting yeast. J. Biol. Chem. 2013, 288, 13082-13092. [CrossRef] [PubMed]

10. Sarafian, V.; Kim, Y.; Poole, R.J.; Rea, P.A. Molecular cloning and sequence of cDNA encoding the pyrophosphate-energized vacuolar membrane proton pump of Arabidopsis thaliana. Proc. Natl. Acad. Sci. USA 1992, 89, 1775-1779. [CrossRef] [PubMed]

11. Rocha Façanha, A.; de Meis, L. Reversibility of $\mathrm{H}^{+}$-ATPase and $\mathrm{H}^{+}$pyrophosphatase in tonoplast vesicles from maize coleoptiles and seeds. Plant Physiol. 1998, 116, 1487-1495. [CrossRef] [PubMed]

12. Marsh, K.; Gonzalez, P.; Echeverría, E. PPi formation by reversal of the tonoplast-bound $\mathrm{H}^{+}$-pyrophosphatase from Valencia orange juice cells. J. Am. Soc. Hortic. Sci. 2000, 125, 420-424.

13. Ferjani, A.; Segami, S.; Horiguchi, G.; Muto, Y.; Maeshima, M.; Tsukaya, H. Keep an eye on PPi: The vacuolar-type $\mathrm{H}^{+}$-pyrophosphatase regulates postgerminative development in Arabidopsis. Plant Cell 2011, 23, 2895-2908. [CrossRef] [PubMed]

14. Gaxiola, R.A.; Regmi, K.; Paez-Valencia, J.; Pizzio, G.; Zhang, S. Plant $\mathrm{H}^{+}$-PPases: Reversible enzymes with contrasting functions dependent on membrane environment. Mol. Plant 2015, 9, 317-319. [CrossRef] [PubMed]

15. Takahashi, K.; Morimoto, R.; Tabeta, H.; Asaoka, M.; Ishida, M.; Maeshima, M.; Tsukaya, H.; Ferjani, A. Compensated Cell Enlargement in fugu 5 is Specifically Triggered by Lowered Sucrose Production from Seed Storage Lipids. Plant Cell Physiol. 2017, 58, 668-678. [CrossRef] [PubMed]

16. Segami, S.; Tomoyama, T.; Sakamoto, S.; Gunji, S.; Fukuda, M.; Kinoshita, S.; Mitsuda, N.; Ferjani, A.; Maeshima, M. Vacuolar $\mathrm{H}^{+}$-Pyrophosphatase and Cytosolic Soluble Pyrophosphatases Cooperatively Regulate Pyrophosphate Levels in Arabidopsis thaliana. Plant Cell 2018, 30, 1040-1061. [CrossRef] [PubMed]

17. Paez-Valencia, J.; Patron-Soberano, A.; Rodriguez-Leviz, A.; Sanchez-Lares, J.; Sanchez-Gomez, C.; Valencia-Mayoral, P.; Diaz-Rosas, G.; Gaxiola, R. Plasma membrane localization of the type I H ${ }^{+}$-PPase AVP1 in sieve element-companion cell complexes from Arabidopsis thaliana. Plant Sci. 2011, 181, 23-30. [CrossRef] [PubMed]

18. Gaxiola, R.A.; Sanchez, C.A.; Paez-Valencia, J.; Ayre, B.G.; Elser, J.J. Genetic manipulation of a "vacuolar" $\mathrm{H}^{+}$-PPase: From salt tolerance to yield enhancement under phosphorus-deficient soils. Plant Physiol. 2012, 159, 3-11. [CrossRef] [PubMed]

19. Pizzio, G.A.; Paez-Valencia, J.; Khadilkar, A.S.; Regmi, K.; Patron-Soberano, A.; Zhang, S.; Sanchez-Lares, J.; Furstenau, T.; Li, J.; Sanchez-Gomez, C.; et al. Arabidopsis type I proton-pumping pyrophosphatase expresses strongly in phloem, where it is required for pyrophosphate metabolism and photosynthate partitioning. Plant Physiol. 2015, 167, 1541-1553. [CrossRef] [PubMed]

20. Khadilkar, A.S.; Yadav, U.P.; Salazar, C.; Shulaev, V.; Paez-Valencia, J.; Pizzio, G.A.; Gaxiola, R.A.; Ayre, B.G. Constitutive and companion cell-specific overexpression of AVP1, encoding a proton-pumping pyrophosphatase, enhances biomass accumulation, phloem loading and long-distance transport. Plant Physiol. 2015, 170, 401-414. [CrossRef] [PubMed]

21. Maeshima, M. Tonoplast transporters: Organization and function. Annu. Rev. Plant Physiol. Plant Mol. Biol. 2001, 52, 469-497. [CrossRef] [PubMed]

22. Kriegel, A.; Andrés, Z.; Medzihradszky, A.; Krüger, F.; Scholl, S.; Delang, S.; Patir-Nebioglu, M.G.; Gute, G.; Yang, H.; Murphy, A.S.; et al. Job sharing in the endomembrane system: Vacuolar acidification requires the combined activity of V-ATPase and V-PPase. Plant Cell 2015, 27, 3383-3396. [CrossRef] [PubMed] 
23. Gaxiola, R.A.; Li, J.; Undurraga, S.; Dang, L.M.; Allen, G.J.; Alper, S.L.; Fink, G.R. Drought- and salt-tolerant plants result from overexpression of the AVP1 $\mathrm{H}^{+}$-pump. Proc. Natl. Acad. Sci. USA 2001, 98, 11444-11449. [CrossRef] [PubMed]

24. Yang, H.; Knapp, J.; Koirala, P.; Rajagopal, D.; Peer, W.A.; Silbart, L.K.; Murphy, A.; Gaxiola, R.A. Enhanced phosphorus nutrition in monocots and dicots over-expressing a phosphorus-responsive type I $\mathrm{H}^{+}$-pyrophosphatase. Plant Biotechnol. J. 2007, 5, 735-745. [CrossRef] [PubMed]

25. Paez-Valencia, J.; Sanchez-Lares, J.; Marsh, E.; Dorneles, L.T.; Santos, M.P.; Sanchez, D.; Winter, A.; Murphy, S.; Cox, J.; Trzaska, M.; et al. Enhanced proton translocating pyrophosphatase activity improves nitrogen use efficiency in romaine lettuce. Plant Physiol. 2013, 161, 1557-1569. [CrossRef] [PubMed]

26. Wang, X.; Wang, H.; Liu, S.; Ferjani, A.; Li, J.; Yan, J.; Yang, X.; Qin, F. Genetic variation in ZmVPP1 contributes to drought tolerance in maize seedlings. Nat. Genet. 2016, 48, 1233-1241. [CrossRef] [PubMed]

27. Schilling, R.K.; Tester, M.; Marschner, P.; Plett, D.C.; Roy, S.J. AVP1: One Protein, Many Roles. Trends Plant Sci. 2017, 22, 154-162. [CrossRef] [PubMed]

28. Karley, A.J.; White, P.J. Moving cationic minerals to edible tissues: Potassium, magnesium, calcium. Curr. Opin. Plant Biol. 2009, 12, 291-298. [CrossRef] [PubMed]

29. Bose, J.; Babourina, O.; Rengel, Z. Role of magnesium in alleviation of aluminium toxicity in plants. J. Exp. Bot. 2011, 62, 2251-2264. [CrossRef] [PubMed]

30. Tang, R.J.; Luan, S. Regulation of calcium and magnesium homeostasis in plants: From transporters to signaling network. Curr. Opin. Plant Biol. 2017, 39, 97-105. [CrossRef] [PubMed]

31. Li, L.G.; Tutone, A.F.; Drummond, R.S.M.; Gardner, R.C.; Luan, S. A novel family of magnesium transport genes in Arabidopsis. Plant Cell 2001, 13, 2761-2775. [CrossRef] [PubMed]

32. Schock, I.; Gregan, J.; Steinhauser, S.; Schweyen, R.; Brennicke, A.; Knoop, V. A member of a novel Arabidopsis thaliana gene family of candidate $\mathrm{Mg}^{2+}$ ion transporters complements a yeast mitochondrial group II intron-splicing mutant. Plant J. 2000, 24, 489-501. [CrossRef] [PubMed]

33. Gebert, M.; Meschenmoser, K.; Svidová, S.; Weghuber, J.; Schweyen, R.; Eifler, K.; Lenz, H.; Weyand, K.; Knoop, V. A root-expressed magnesium transporter of the MRS2/MGT gene family in Arabidopsis thaliana allows for growth in low- $\mathrm{Mg}^{2+}$ environments. Plant Cell 2009, 21, 4018-4030. [CrossRef] [PubMed]

34. Conn, S.J.; Conn, V.; Tyerman, S.D.; Kaiser, B.N.; Leigh, R.A.; Gilliham, M. Magnesium transporters, MGT2/MRS2-1 and MGT3/MRS2-5, are important for magnesium partitioning within Arabidopsis thaliana mesophyll vacuoles. New Phytol. 2011, 190, 583-594. [CrossRef] [PubMed]

35. Li, L.G.; Sokolov, L.N.; Yang, Y.H.; Li, D.P.; Ting, J.; Pandy, G.K.; Luan, S. A mitochondrial magnesium transporter functions in Arabidopsis pollen development. Mol. Plant 2008, 1, 675-685. [CrossRef] [PubMed]

36. Li, J.; Huang, Y.; Tan, H.; Yang, X.; Tian, L.; Luan, S.; Chen, L.; Li, D. An endoplasmic reticulum magnesium transporter is essential for pollen development in Arabidopsis. Plant Sci. 2015, 231, 212-220. [CrossRef] [PubMed]

37. Chen, J.; Li, L.G.; Liu, Z.H.; Yuan, Y.J.; Guo, L.L.; Mao, D.D.; Tian, L.F.; Chen, L.B.; Luan, S.; Li, D.P. Magnesium transporter AtMGT9 is essential for pollen development in Arabidopsis. Cell Res. 2009, 19, 887-898. [CrossRef] [PubMed]

38. Xu, X.F.; Wang, B.; Lou, Y.; Han, W.J.; Lu, J.Y.; Li, D.D.; Li, L.G.; Zhu, J.; Yang, Z.N. Magnesium transporter 5 plays an important role in $\mathrm{Mg}$ transport for male gametophyte development in Arabidopsis. Plant J. 2015, 84, 925-936. [CrossRef] [PubMed]

39. Mao, D.; Chen, J.; Tian, L.; Liu, Z.; Yang, L.; Tang, R.; Li, J.; Lu, C.; Yang, Y.; Shi, J.; et al. Arabidopsis transporter MGT6 mediates magnesium uptake and is required for growth under magnesium limitation. Plant Cell 2014, 26, 2234-2248. [CrossRef] [PubMed]

40. Yan, Y.W.; Mao, D.D.; Yang, L.; Qi, J.L.; Zhang, X.X.; Tang, Q.L.; Li, Y.P.; Tang, R.J.; Luan, S. Magnesium transporter MGT6 plays an essential role in maintaining magnesium homeostasis and regulating high magnesium tolerance in Arabidopsis. Front. Plant Sci. 2018, 9, 274-286. [CrossRef] [PubMed]

41. Oda, K.; Kamiya, T.; Shikanai, Y.; Shigenobu, S.; Yamaguchi, K.; Fujiwara, T. The Arabidopsis Mg transporter, MRS2-4, is essential for Mg homeostasis under both low and high Mg conditions. Plant Cell Physiol. 2016, 57, 754-763. [CrossRef] [PubMed]

42. Tang, R.J.; Zhao, F.G.; Garcia, V.J.; Kleist, T.J.; Yang, L.; Zhang, H.X.; Luan, S. Tonoplast CBL-CIPK calcium signaling network regulates magnesium homeostasis in Arabidopsis. Proc. Natl. Acad. Sci. USA 2015, 112, 3134-3139. [CrossRef] [PubMed] 
43. Li, J.; Yang, H.; Peer, W.A.; Richter, G.; Blakeslee, J.; Bandyopadhyay, A.; Titapiwantakun, B.; Undurraga, S.; Khodakovskaya, M.; Richards, E.L.; et al. Arabidopsis $\mathrm{H}^{+}$-PPase AVP1 regulates auxin-mediated organ development. Science 2005, 310, 121-125. [CrossRef] [PubMed]

44. Segami, S.; Makino, S.; Miyake, A.; Asaoka, M.; Maeshima, M. Dynamics of vacuoles and $\mathrm{H}^{+}$-pyrophosphatase visualized by monomeric green fluorescent protein in Arabidopsis: Artifactual bulbs and native intravacuolar spherical structures. Plant Cell 2014, 26, 3416-3434. [CrossRef] [PubMed]

45. Shaul, O. Magnesium transport and function in plants: The tip of the iceberg. Biometals 2002, 15, 307-321. [CrossRef]

46. Li, Z.G.; Baldwin, C.M.; Hu, Q.; Liu, H.; Luo, H. Heterologous expression of Arabidopsis $\mathrm{H}^{+}$-pyrophosphatase enhances salt tolerance in transgenic creeping bentgrass (Agrostis stolonifera L.). Plant Cell Environ. 2010, 33, 272-289. [CrossRef] [PubMed]

47. Schilling, R.K.; Marschner, P.; Shavrukov, Y.; Berger, B.; Tester, M.; Roy, S.J.; Plett, D.C. Expression of the Arabidopsis vacuolar $\mathrm{H}^{+}$-pyrophosphatase gene (AVP1) improves the shoot biomass of transgenic barley and increases grain yield in a saline field. Plant Biotechnol. J. 2014, 12, 378-386. [CrossRef] [PubMed]

48. Tang, R.J.; Liu, H.; Yang, Y.; Yang, L.; Gao, X.S.; Garcia, V.J.; Luan, S.; Zhang, H.X. Tonoplast calcium sensors CBL2 and CBL3 control plant growth and ion homeostasis through regulating V-ATPase activity in Arabidopsis. Cell Res. 2012, 22, 1650-1665. [CrossRef] [PubMed]

49. Fukuda, M.; Segami, S.; Tomoyama, T.; Asaoka, M.; Nakanishi, Y.; Gunji, S.; Ferjani, A.; Maeshima, M. Lack of $\mathrm{H}^{+}$-pyrophosphatase prompts developmental damage in Arabidopsis leaves on ammonia-free culture medium. Front. Plant Sci. 2016, 7, 819. [CrossRef] [PubMed]

(C) 2018 by the authors. Licensee MDPI, Basel, Switzerland. This article is an open access article distributed under the terms and conditions of the Creative Commons Attribution (CC BY) license (http:/ / creativecommons.org/licenses/by/4.0/). 